\title{
Pattern of myelinated fibre loss in the sural nerve in neuropathy related to Type 1 (insulin-dependent) diabetes
}

\author{
J.G.Llewelyn ${ }^{1}$, P. K. Thomas ${ }^{1}$, S.G. Gilbey ${ }^{2}$, P.J.Watkins ${ }^{2}$ and J.R. Muddle ${ }^{1}$ \\ ${ }^{1}$ Department of Neurological Science, Royal Free Hospital School of Medicine, and \\ ${ }^{2}$ Diabetic Department, King's College Hospital, London, UK
}

\begin{abstract}
Summary. Sural nerve biopsies were obtained from 17 diabetic patients with neuropathy. All patients except three had both a symmetric distal sensory and autonomic polyneuropathy related to Type 1 (insulin-dependent) diabetes mellitus; 3 patients had a purely sensory polyneuropathy. Mean age was 34.5 years (range $18-53$ years). The biopsies were compared with specimens from an age-matched control series. Myelinated fibre loss in the diabetic nerves was found to be nonuniform. Although patchy fibre loss has been considered to favour a vascular basis, an identical pattern of nonuniform
\end{abstract}

loss was observed in a series of sural nerve biopsies from patients with Type I hereditary motor and sensory neuropathy, a subgroup within the spectrum of peroneal muscular atrophy, mainly of autosomal dominant inheritance, and a condition in which a vascular causation can be discounted. Possible reasons for nonuniform fibre loss other than vascular disease are discussed.

Key words: Diabetic neuropathy, hereditary motor and sensory neuropathy, sural nerve.
The central question relating to diabetic neuropathy is its cause. One view has been that the focal and multifocal neuropathies that are encountered, particularly in the older diabetic patient, are likely to have a vascular basis. Some focal neuropathies may be related to an abnormal susceptibility to injury from compression. The commoner sensory and autonomic polyneuropathy has been considered more probably to result from metabolic factors [1]. Recently, increasing evidence has been amassed suggesting that ischaemia is also important in the causation of diffuse polyneuropathies. In patients with a distal sensorimotor polyneuropathy, postmortem examination showed that the symmetric deficit was produced as a result of multifocal lesions [2]. Sural nerve biopsies have shown that the number of 'closed' capillaries is greater in patients with diabetic neuropathy than in nerves from age-matched control subjects and is positively correlated with the severity of the neuropathy [3]. In biopsies from 36 patients, the pattern of nerve fibre loss was both multifocal and diffuse $[4,5]$, the former pattern again suggesting a vascular basis. In another postmortem study, multifocal lesions in the lumbosacral trunks and the tibial nerve, but not in the sural nerve, were observed to be more numerous in 16 patients with diabetic neuropathy than in nondiabetic subjects [6]. Finally, intraluminal vascular changes have been recorded in cases of diabetic neuropathy $[7,8]$.
Most of these studies, however, have been performed on older patients. Mean age in the autopsied series reported by Johnson et al. [6] was 64 years. In the nerve biopsy study by Dyck et al. [5], median age was 52 years in men with Type 1 (insulin-dependent) diabetes (only 3 women were included); it was 56 years for men and 55 years for women with Type 2 (non-insulin-dependent) diabetes. In the present investigation, observations were therefore performed on a series of younger patients with diabetic neuropathy. All had Type 1 diabetes and were less than 54 years of age. The pattern of myelinated fibre loss in the sural nerve was assessed in comparison with the findings in agematched control subjects without neuropathy and in sural nerve biopsies from patients with Type I hereditary motor and sensory neuropathy, a condition in which a vascular basis has not been proposed.

\section{Subjects and methods}

All diabetic patients ( 5 male, 12 female; mean age 34.5 years, range 18-53 years) had clinical and electrophysiological evidence of a distal symmetric, predominantly sensory polyneuropathy; 14 of the 17 patients had significant autonomic dysfunction either clinically or on formal testing. The clinical and biochemical data at, or near the time of, nerve biopsy are given in Table 1 . Only 2 patients had clinical evidence of peripheral vascular disease. Case $8 \mathrm{had}$ absent foot pulses but no symptoms of vascular insufficiency. Case 11 had typical claudication and subsequent rest pain that led to amputation. 


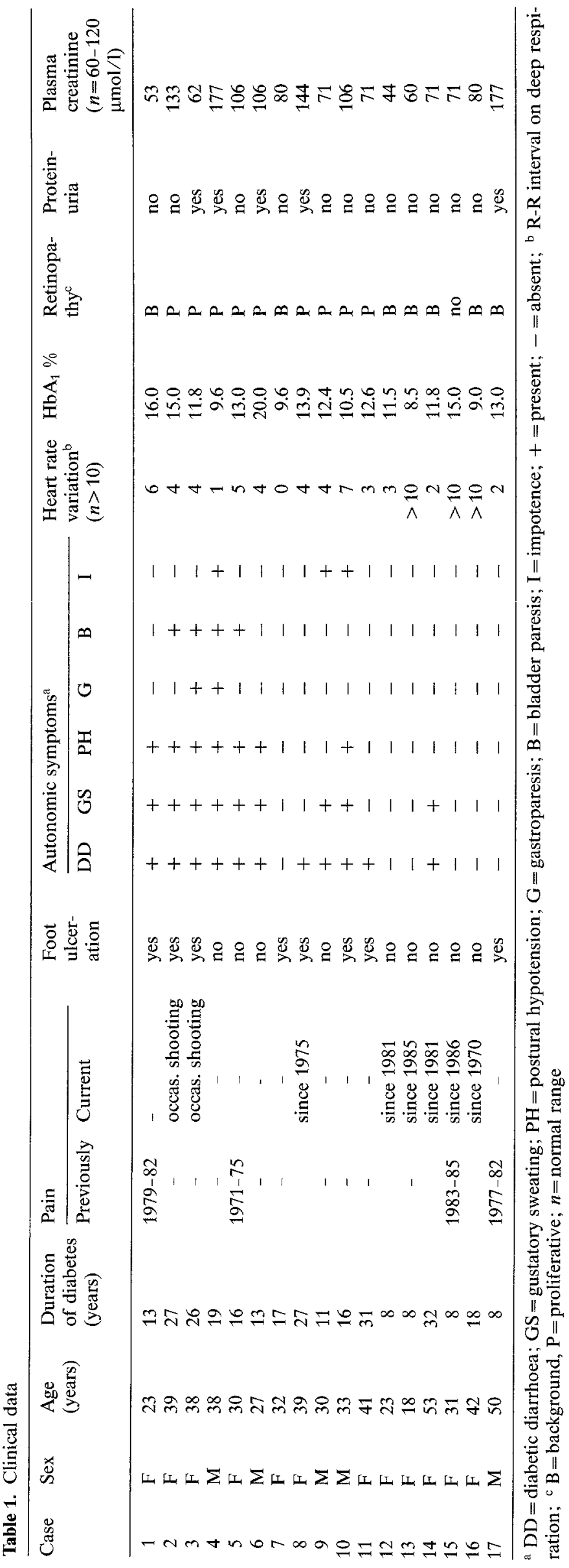

Table 2. Sural nerve myelinated fibre (MF) density

\begin{tabular}{lclll}
\hline & $\begin{array}{l}\text { No. of } \\
\text { cases }\end{array}$ & $\begin{array}{l}\text { Mean age and } \\
\text { range (years) }\end{array}$ & $\begin{array}{l}\text { Mean MF/frame } \\
\text { and range }\end{array}$ & $\begin{array}{l}\text { Mean fibre density } \\
\left(\mathrm{MF} / \mathrm{mm}^{2}\right) \text { and range }\end{array}$ \\
\hline Control & 6 & $38.3(21-48)$ & $48.6(43.4-53.7)$ & $10859(9061-12746)$ \\
Diabetic & 17 & $34.5(18-53)$ & $9.9(1.2-30.6)$ & $2289(265-7660)$ \\
HMSN & 9 & $36.5(11-58)$ & $11.0(4.1-28.2)$ & $2340(831-5718)$ \\
\hline
\end{tabular}

HMSN = Type I hereditary motor and sensory neuropathy

There was no evidence of focal cranial, thoracoabdominal or limb neuropathy in any of the cases. All patients were on highly purified bovine or porcine insulin. Sural nerve fascicular biopsies were obtained with informed consent and had the approval of the Ethics Committee at King's College Hospital.

Total sural nerve biopsies were obtained from six organ donor cases ( 3 male, 3 female; mean age 38.3 years, range $21-48$ years) at the time of organ donation before circulatory arrest with the permission of next of kin and the approval of the Ethics Committee at the Royal Free Hospital. Sural nerve fascicular biopsies previously obtained from 9 patients ( 4 male, 5 female; mean age 36.5 years, range 11-58 years) with Type I hereditary motor and sensory neuropathy were also examined. The criteria for diagnosis were those given by Harding and Thomas [9].

The biopsies were all obtained from a site immediately posterior to the lateral malleolus. The specimens were fixed in $3 \%$ glutaraldehyde in PIPES buffer [10] with $2 \%$ sucrose. After postfixation in 1\% osmium tetroxide in PIPES buffer containing $1.5 \%$ potassium ferricyanide, the specimens were dehydrated through increasing concentrations of ethanol and embedded in Araldite via 1,2-epoxyproprane. Transverse semithin sections were cut and stained with thionin and acridine orange [11].

The morphometric observations were performed using a Kontron MOP Videoplan image analysis system connected to a monitor screen via a TV camera attached to a Leitz optical microscope. Using a X 40 objective, each fascicle was traversed horizontally and vertically using a fixed frame. All possible frames were assessed and for each frame the endoneurial area and myelinated nerve fibre (MF) content were recorded.

\section{Statistical analysis}

To assess whether fibre loss was uniform or nonuniform, following Dyck et al. [12], we have employed two statistical measures, coefficient of variation and index of dispersion [13]. The coefficient of variation $(\mathrm{CV})$ is given by $\mathrm{s} / \mathrm{x}$, where $\mathrm{s}$ and $\mathrm{x}$ are the standard deviation and mean of the fibre density. The index of dispersion (ID) is given by $A_{H} s^{2} / x$, where $A_{H}$ is the harmonic mean. If the fibres are distributed randomly, $\mathrm{A}_{H} \mathrm{~s}^{2}$ will, on average, be equal to $\mathrm{x}$, and the ID will approximate to 1 ; if fibres are clustered, ID will be greater than 1. Statistical analysis was carried out using the Mann-Whitney $U$ test.

\section{Results}

The diabetic group closely matched the organ-donor control group and the patients with hereditary motor and sensory neuropathy for age (Table 2). The MF density for the control group ranged from $9,061-12,746 / \mathrm{mm}^{2}$. The reduction in MF density was comparable in the diabetic and hereditary motor and sensory neuropathy groups, the mean values being $2,289 / \mathrm{mm}^{2}$ and $2,340 / \mathrm{mm}^{2}$ respectively. A transverse section of a normal sural nerve fascicle is shown in Figure $1 \mathrm{~A}$. The MF loss in the diabetic nerves affected 


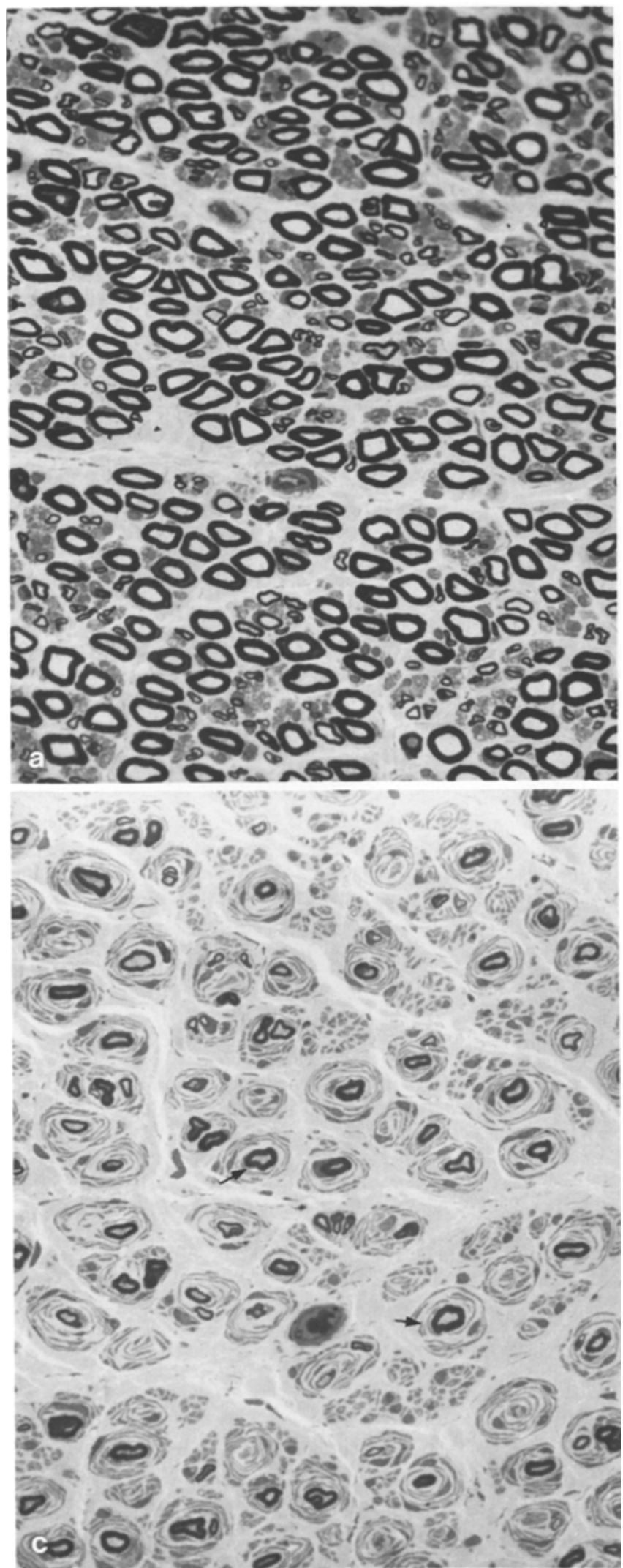

both large and small fibres and some regenerative clusters were present in most cases (Fig. 1B); endoneurial oedema was not evident. In the hereditary motor and sensory neuropathy cases (Fig.1C), there was a

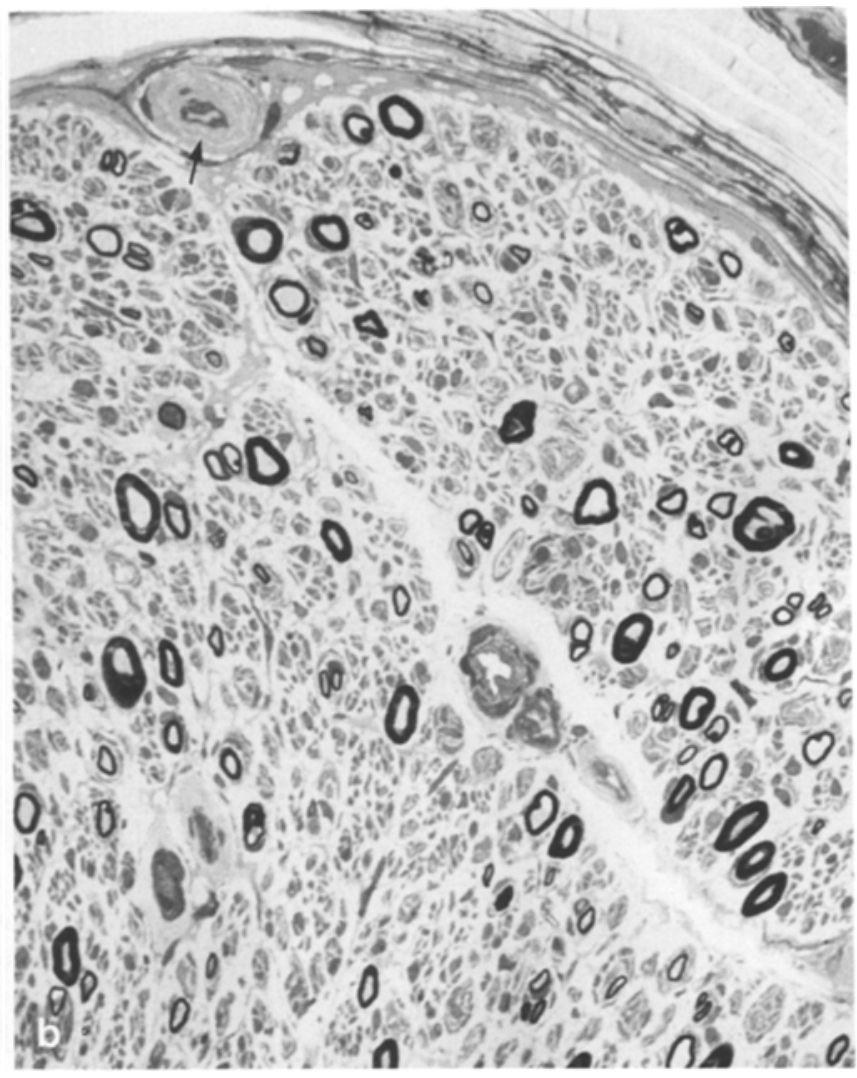

Fig.1. a Transverse section of normal sural nerve from a female subject aged 38 years, $X 425$. b Transverse section of sural nerve from a diabetic patient aged 53 years. An endoneurial capillary surrounded by thickened basement membrane is arrowed, $X 425$. c Transverse section of sural nerve from a patient with Type I hereditary motor and sensory neuropathy, aged 38 years. Many of the myelinated fibres are surrounded by concentrically proliferated Schwann cells (onion bulbs) (arrows). Thionin and acridine orange, X 425.

Table 3. Mean values and ranges for coefficient of variation $(\mathrm{CV})$ and index of dispersion (ID) for myelinated fibres in sural nerve

\begin{tabular}{lll}
\hline & Mean CV & Mean ID \\
\hline Control & $17.4(14.8 \pm 23.6)$ & $0.97(0.74 \pm 1.36)$ \\
Diabetic & $41.7(14.6 \pm 99.8)^{\mathrm{a}}$ & $1.01(0.18 \pm 2.56)^{\mathrm{c}}$ \\
HMSN & $43.8(21.1 \pm 80.8)^{\mathrm{b}}$ & $1.21(0.38 \pm 1.82)^{\mathrm{c}}$ \\
\hline
\end{tabular}

Significantly different from controls ${ }^{\mathrm{a}} p<0.001{ }^{\mathrm{b}} p<0.0002{ }^{\mathrm{c}}$ not significant; HMSN = Type I hereditary motor and sensory neuropathy

predominant reduction in density for larger fibres $(>$ $7 \mu \mathrm{m})$ and hypertrophic changes ('onion bulbs') were present in the majority.

The mean number of MF/frame was significantly and comparably reduced in both the diabetic and hereditary motor and sensory neuropathy groups as compared with the control group (Table 2). The variability of the MF distribution within each fascicle was estimated by comparing their $\mathrm{CV}$ and ID among the frames (Table 3 ). The CV was increased 2.4-fold in the diabetic patients $(p<0.001)$, this value being similar to 
that obtained by Dyck et al. [5]. A similar increase (X 2.52) was observed in the CV derived from the hereditary motor and sensory neuropathy cases $(p<$ 0.0002 ). Although the ID was greater in both the diabetic neuropathy and hereditary motor and sensory neuropathy nerves than in the control subjects, the increases did not reach statistical significance.

\section{Discussion}

Critical appraisal of recent pathological studies [4-6] implicating vascular factors in the causation of diabetic polyneuropathy concluded that although strong evidence had been accumulated, the results had been drawn from elderly populations of diabetic patients and could not therefore be applied to younger diabetic patients with neuropathy without further study [14]. Using CV and ID as parameters of the distribution of MF loss, we have applied these measures not only to a younger group of diabetic patients and age-matched control subjects, but also to patients with an inherited polyneuropathy - Type I hereditary motor and sensory neuropathy - in which a vascular pathogenesis has not been implicated. Our results clearly show that the CV is significantly raised in this population of young diabetic patients to a similar degree as was found previously by Dyck et al. [5], whereas the ID, although raised, did not differ significantly from the control subjects, again as was found previously [5].

Variation in the degree of fibre loss between fascicles in a biopsy from a diabetic patient was noted by Thomas and Lascelles [15] in a case with clear clinical evidence of a multifocal neuropathy in which the biopsied nerve had been affected. Postmortem examination in two diabetic patients with severe peripheral vascular disease and a 'predominantly' symmetric sensorimotor neuropathy [2] also demonstrated multifocal fibre loss at proximal sciatic nerve level, but not at root or more distal levels. In sural nerve biopsies from 32 patients with diabetic neuropathy, Dyck et al. [5] found only occasionally that a sector or whole fascicle had few or no MFs. Their illustration shows a very small facicle devoid of MFs with a moderate reduction of MFs in an adjacent larger fascicle. We found such changes in only the oldest patient (aged 53 years) where two small fascicles were more severely depleted. Caution has to be exercised in interpreting fibre density in very small fascicles [16, 17]. In contrast, Johnson et al. [6], in an autopsy study, found that over half of their patients had evidence of focal loss (defined as a zone of reduced MF density involving at least $20 \%$ of the fascicle) at sural nerve level. This discrepancy may be explained by the fact that the study by Johnson et al. examined the whole sural nerve whereas that by Dyck et al. [5] was confined to fascicular biopsies. It can, therefore, be accepted that in the older patient with diabetic neuropathy, there is good evidence of sectorial loss of MFs that is most likely to be ischaemic in origin. Johnson et al. [6] have shown that focal destruction of the perineurium with consequent outgrowth of fibres into the epineurium may occur in diabetic neuropathy. This again is most easily explicable in terms of ischaemic damage.

The present study examined a younger population of patients with diabetic neuropathy who had a symmetric sensory and autonomic polyneuropathy. The CV was increased in comparison with age-matched control nerves, indicating that the fibre loss was patchy. The interesting finding, however, was that an almost identical increase in the $\mathrm{CV}$ was obtained in the patients with Type I hereditary motor and sensory neuropathy in whom it would be difficult to attribute the multifocal nature of the fibre loss to ischaemia. It will be of interest to examine other nonischaemic polyneuropathies in the same age range.

The spatial distribution of fibres in normal human peripheral nerve is nonuniform [17], introducing difficulties when sampling procedures are adopted. This is unlikely to interfere with the present results. A sampling procedure was not used, all possible frames being studied. Our results have shown that both in diabetic neuropathy and in Type I hereditary motor and sensory neuropathy, the loss of fibres compared with age-matched control nerve is nonuniform. The explanation for this unexpected finding is not yet certain. One possibility would be spatial segregation of fibres in terms of ultimate distribution. If a neuropathy is length-related, that is, preferentially affecting the longest fibres, nonrandom loss might then be expected. Both diabetic polyneuropathy and Type I hereditary motor and sensory neuropathy have a predominantly distal distribution. Some uncertainty exists as to the degree of topographical segregation of fibres within nerve trunks. Although previously the consensus was that there is constant mixing of nerve fibres along nerve trunks [18], recent observations suggest that a significant degree of segregation exists [19-21]. Other studies have concluded that this is restricted to the periphery. Thus, Dyer and Duncan [22], in the recurrent laryngeal nerve of the horse, found evidence of segregation of fibres destined for individual laryngeal muscles at distances of up to $10-15 \mathrm{~cm}$ from the muscles. The present observations were made on the sural nerve at the ankle; this is towards the periphery of the distribution of the nerve.

Clinical considerations make it unlikely that the common sensory and autonomic polyneuropathy of diabetes has a primarily vascular causation. Chronic hypoxia in the human does not cause a clinically significant neuropathy, although minor subclinical abnormalities of nerve conduction may be detectable, and occasionally patients show a mild neuropathy for which no other cause is evident [23-25]. Neuropathies with a known vascular basis, such as those related to vasculitis or small vessel occlusion are characteristical- 
ly multifocal, but may summate to produce a symmetric distribution. They tend, however, predominantly to affect motor function rather than sensory, autonomic function being relatively spared. This pattern is true of the cases of multifocal distal lower limb diabetic neuropathy that Timperley et al. [8] related to microvascular disease. It is also true of diabetic lower limb proximal motor neuropathy [26]. These syndromes therefore may well be vascular in origin, as may focal third cranial nerve lesions [27].

For the sensory and autonomic polyneuropathy a mechanism has to be sought that selectively or preferentially affects the function of these fibres or their parent cell bodies in the dorsal root and autonomic ganglia. Metabolic differences between these neurons and lower motor neurons could exist as the cell bodies of anterior horn cells are within the central nervous system whereas the sensory and autonomic neurons have their cell bodies in the peripheral nervous system. The metabolic abnormalities so far identified in the peripheral nervous system, such as sorbitol accumulation [28], myo-inositol deficiency [29] and reduced sodium, potassium-ATPase activity $[30,31]$ affect both motor and sensory fibres and may therefore not be relevant for the development of degenerative neuropathy. They are clearly implicated in the small changes in nerve conduction velocity that occur and which can be reversed by metabolic manipulation both in animals $[32,33]$ and man [34]. Abnormalities of axonal transport are known to exist [35-39], but there is no indication thus far of any selective effect on sensory and autonomic fibres. They are known to affect both sensory [39] and motor [37] fibres.

In summary, the present results reveal no difference in the pattern of fibre loss in the sural nerve between patients aged less than 53 years with sensory and autonomic polyneuropathy related to insulin-dependent diabetes and cases of Type I hereditary motor and sensory neuropathy in which a vascular cause can be discounted. Clinical considerations suggest that diabetic neuropathy is heterogeneous, with both metabolic and vascular factors being involved in its causation, their relative importance varying between cases.

Acknowledgements. Financial support from Pfizer (UK) Ltd is gratefully acknowledged. The image analysis equipment was purchased with the aid of grants from Ciba-Geigy Ltd, Basel, and the London University Central Research Fund. JGL was a Pfizer Research Fellow.

\section{References}

1. Thomas PK, Eliasson SG (1981) Diabetic neuropathy. In: Dyck PJ, Thomas PK, Lambert EH, Bunge R (eds) Peripheral Neuropathy, 2nd edn. W.B. Saunders, Philadelphia, pp 1773-1810

2. Sugimura K, Dyck PJ (1982) Multifocal fiber loss in proximal sciatic nerve in symmetric distal diabetic neuropathy. J Neurol Sci 53: 501-509

3. Dyck PJ, Hansen S, Karnes J, O'Brien P, Yasuda H, Winde- bank A, Zimmerman B (1985) Capillary number and percentage closed in human diabetic sural nerve. Proc Natl Acad Sci USA 82: $2513-2517$

4. Dyck PJ, Karnes JL, O'Brien P, Okazaki H, Lais A, Engelstad J (1986) The spatial distribution of fiber loss in diabetic polyneuropathy suggests ischemia. Ann Neurol 19: 440-449

5. Dyck PJ, Lais A, Karnes IL, O'Brien P, Rizza R (1986) Fiber loss is primary and multifocal in sural nerves in diabetic polyneuropathy. Ann Neurol 19: 425-439

6. Johnson PC, Doll SC, Cromey DW (1986) Pathogenesis of diabetic neuropathy. Ann Neurol 19: 450-457

7. Timperley WR, Ward JD, Preston FE, Duckworth T, O'Malley BC (1976) A reassessment of vascular factors in relation to intravascular coagulation. Diabetologia 12:237-243

8. Timperley WR, Boulton AJ, Davies-Jones GA, Jarratt JA, Ward ID (1985) Small vessel disease in progressive neuropathy associated with good metabolic control. J Clin Pathol 38: $1030-1038$

9. Harding AE, Thomas PK (1980) The clinical features of hereditary motor and sensory neuropathy, types I and II. Brain 103: 259-280

10. Baur PS, Stacey TR (1977) The use of PIPES buffer in the fixation of mammalian and marine tissues for electron microscopy. J Microsc 109: 315-327

11. Sievers J (1971) Basic two-dye stains for epoxy-embedded 0.3-1 um sections. Stain Technol 46: 195-199

12. Dyck PJ, Karnes J, O'Brien PC, Nukuda H, Lais A, Low P (1984) Spatial patterns of nerve fiber abnormality indicative of pathologic mechanisms. Am J Pathol 117: 225-238

13. Perry JN, Mead R (1979) On the power of the index of dispersion test to detect spatial pattern. Biometrics 35:613-622

14. Thomas PK (1987) Vascular factors in the causation of diabetic neuropathy. TINS 10:6-7

15. Thomas PK, Lascelles RG (1966) The pathology of diabetic neuropathy. Q J Med 35: 485-509

16. O'Sullivan DJ, Swallow M (1968) The fibre size and content of the radial and sural nerves. J Neurol Neurosurg Psychiatry 31: 464-470

17. Saxod R, Torch S, Vila A, Laurent A, Stoebner P (1985) The density of myelinated fibres is related to fascicle diameter in human superficial peroneal nerve. Statistical study of 41 normal samples. J Neurol Sci 71: 49-64

18. Sunderland S (1978) Nerve and Nerve Injuries, 2nd edn. Churchill Livingstone, Edinburgh

19. Ueyama $T$ (1978) The topography of root fibres within the sciatic nerve of the dog. J Anat 127:277-290

20. Jabalay ME, Wallace WH, Heckler FR (1980) Internal topography of major nerves of the forearm and hand: a current view. $J$ Hand Surg 5: 1-18

21. Schady W, Ochoa JL, Torejörk HE, Chen LS (1983) Peripheral projection of fascicles in the human median nerve. Brain 106: $745-760$

22. Dyer KR, Duncan IC (1987) The intraneural distribution of myelinated fibres in the equine recurrent laryngeal nerve. Brain 110 $1531-1543$

23. Appenzeller O, Parks RD, MacGee J (1968) Peripheral neuropathy in chronic disease of the respiratory tract. Am J Med 44: 873-880

24. Faden A, Mendoza E, Flynn F (1981) Subclinical neuropathy associated with chronic obstructive pulmonary disease. Possible pathophysiologic role of smoking. Arch Neurol 38: 639-642

25. Paramelle B, Vila A, Pollak P, Muller P, Gavelle D, Reymond F, Brambilla C, Stoebner P (1986) Fréquence des polyneuropathies dans les bronchopneumopathies chroniques obstructives. Presse Méd 15: $563-567$

26. Raff MC, Sangalang V, Asbury AK (1968) Ischemic mononeuropathy multiplex associated with diabetes mellitus. Arch Neurol (Chic) 18: 487-499

27. Asbury AK, Aldredge H, Hershberg R, Fisher CM (1970) Oculomotor palsy in diabetes mellitus: a clinicopathological study. Brain 93: $555-566$ 
28. Gabbay KH (1973) In: Camerini-Davalos RA, Cole HS (eds) Vascular and Neurological Changes in Early Diabetes. Academic Press, New York, pp 417-424

29. Greene DA, DeJesus PV, Winegrad I (1975) Effects of insulin and dietary myoinositol on impaired peripheral motor nerve conduction velocity in acute streptozotocin diabetes. J Clin Invest 55: $1326-1336$

30. Das PK, Bray GM, Aguayo AJ, Rasminsky M (1976) Diminished ouabain sensitive sodium-potassium ATPase activity in sciatic nerves of rats with streptozotocin-induced diabetes. Exp Neurol 53: $285-288$

31. Greene DA, Lattimer DA (1983) Na/K ATPase defect in diabetic rat peripheral nerve: correction by myo-inositol administration. $\mathrm{J}$ Clin Invest 72: 1058-1063

32. Finegold D, Lattimer S, Nolle S, Bernstein M, Greene D (1983) Polyol pathway activity and myo-inositol metabolism. Diabetes 32: $988-992$

33. Tomlinson DR, Holmes PR, Mayer JH (1982) Reversal by treatment with an aldose reductase inhibitor, of impaired axonal transport and motor nerve conduction velocity in experimental diabetes. Neurosci Lett 31: 189-193

34. Judzewitsch R, Jaspan JB, Pfeifer MA, Polonsky KS, Halar E, Vukadinovic C, Richton S, Gabbay K, Rubenstein AH, Porte Jr D (1981) Inhibition of aldose reductase improves motor nerve conduction velocity in diabetics. Diabetes 30 [Suppl 1]: 30A

35. Jakobsen J, Sidenius P (1980) Transport of structural proteins in streptozotocin diabetic rats. J Clin Invest 66: 292-297
36. Jakobsen J, Brimijoin S, Sau K, Sidenius P, Wells D (1981) Retrograde axonal transport of transmitted enzymes, fucose-labelled protein, and nerve growth factor in streptozotocin-diabetic rats. Diabetes 30: 797-803

37. Mayer JH, Tomlinson DR, McLean WG (1984) Slow orthograde axonal transport of radiolabelled protein in sciatic motoneurons of rats with short-term experimental diabetes: effects of treatment with an aldose reductase inhibitor or myo-inositol. J Neurochem 43: 1265-1270

38. Vitadello M, Filliatrea G, Gupont JL, Hassig R, Gorio A, Di Giamberardino L (1985) Altered axonal transport of cytoskeletal proteins in the mutant diabetic mouse. $\mathbf{J}$ Neurochem $45: 860-868$

39. Tomlinson DR, Sidenius P, Larsen JR (1986) Slow component a of axonal transport, nerve myo-inositol, and aldose reductase inhibition in streptozotocin-diabetic rats. Diabetes 35: 398-402

Received: 27 October 1987

and in revised form: 13 January 1988

\section{Prof. P. K. Thomas}

Department of Neurological Science

Royal Free Hospital School of Medicine

Rowland Hill Street

London NW3 2PF

UK 